\title{
Oxirane Ring Opening of Rubber (Hevea Brasiliensis) Seed Oil by Perfomic Acid
}

\author{
O.R. Obanla, J.D. Udonne, O.O. Ajani, M.E. Ojewumi O.J. Omodara
}

\begin{abstract}
Studies on the epoxidation of rubber (Hevea brasiliensis) seed oil, a renewable source with formic acid was performed in the presence of $30 \%$ hydrogen peroxide at a of temperature $40,50,60,70{ }^{\circ} \mathrm{C}$. The process is favoured by an increase in temperature forming a product with high oxirane content which is as a result of mole ratios of formic acid and hydrogen peroxide. Products of high oxirane content are commercialy viable in the production of polyvinyl chloride $(P V C)$. Natural rubber and other products can be obtained from this in- situ technique. Studies in this research shows that the rate of epoxidation increases with an increase in temperature. Oxirane values of 2.30, 3.62 and 4.73 for the various temperature. However high oxirane content of 6.22 was obtained at $70{ }^{\circ} \mathrm{C}$ which is in line with literature. FTIR analysis was also carried out on the epoxidized rubber seed oil which shows the peaks of oxirane cleavage.
\end{abstract}

Keywords: Epoxidation, oxirane content, performic acid and rubber seed oil.

\section{INTRODUCTION}

Sustainable materials are well known to be environmental friendly, inexhaustible, cheap and bountiful [1]. The utilization of these raw materials in various areas has fascinated the responsiveness of many researches due to their potentials as an alternative of petroleum chemical derivatives [2]. The development of this biodegradable material has made it achievable to perform a broad study on the chemical composition and the properties of these vegetable oils [3\&4]. In Nigeria, natural oil reliant industries solely rely on importation of oils like castor oil and soybean oil which are quite costly. The readily available oils like coconut oil, groundnut oil and palmkernel oil are in short supply beacase they are cultivated basically for consumption [5-8].

Revised Manuscript Received on November 06, 2019.

O.R. Obanla. Department of Chemical Engineering, Covenant University, Ota, Ogun State, Nigeria. Email: oyinlola.oresegun@covenantuniversity.edu.ng

J.D. Udonne*, Department of Chemical and Polymer Engineering, Lagos State University, Nigeria

O.O. Ajani*, Department of Chemistry, Covenant University, Ota, Ogun State, Nigeria

M.E. Ojewumi*. Department of Chemical Engineering, Covenant University, Ota, Ogun State, Nigeria. Email:

O.J. Omodara*. Department of Chemical Engineering, Covenant University, Ota, Ogun State, Nigeria. Email:
Rubber seed oil has little commercial worth in Nigeria to the best of our realization. Nigeria has the ability of producing over 15,000 tons of rubber seed oil (RSO) anually $[9,10]$. Earlier research studies have reveals that rubber seed oil is a prospective raw material for binders in surface coatings [9], as printing inks [7\&10], biodiesel [9,14-16] processing aid in polymer compounding [11] and manufacture of metallic soaps [12]. The unsaturated fatty acids of this vegetable oils are rich in linolenic and oleic acid. The double bonds present in the fatty acid can be replaced with funtional groups like the epoxides [13\&15]. Rubber seed oil is used in this case. The desired epoxidized oil can be used as a multifuctional additive for rubber compounding [5\&11]. In this study, the synthesis of epoxidized rubber seed oil was carried out by maintaining a particular temperature. The physico chemical properties and spectroscopic data of the product were also established. However, vast work have been reported on the epoxidation of RSO by acetic acid $[3,5,6,11]$ and neither of these reports encompasses the kinetic properties of the finished products. Epoxidation is the reaction of an organic acid with a double bond to form a cyclic three membered ring structure called an epoxide [3\&5]. Nevertheless, this paper extends the study of epoxidation of rubber seed oil by substituting acetic acid for formic acid. The organic acid shuttles the active oxygen between the aqueous phase to the oil layer. The research investigates the epoxidization of rubber sed oil by performic acid generated in situ.

\section{METHODOLOGY}

Crude rubber seed oil (RSO) used in this research was obtained by mechanical expression method. Formic acid (99.5\%) obatined from Sigma Aldrich, Poole, England, hydrobromic acid (AR) obtained from Riendel - de Haen and hydrogen peroxide (30\%) from MERCK were used without further purification in this study.

\section{A. Preparation of epoxidized rubber seed oil}

ERSO was prepared using calculated amount of rubber seed oil, containing $90 \%$ formic acid were placed in a quick fit flask, as shown below in Figure 1a. The flask was continuously stirred and allowed to attain the optimum temperature (controlled to better than $\pm 2{ }^{\circ} \mathrm{C}$ equilibration) and $30 \%$ hydrogen peroxide $(80 \mathrm{ml})$ was added to the oil dropwise with a dropping funnel for over 30 minutes. The stirring rate was maintained at $400 \mathrm{rpm}$ so that oil mixture will be finely dispersed as shown below figure $1 \mathrm{~b}$.

Published By: 
Oxirane Ring Opening of Rubber (Hevea Brasiliensis) Seed Oil by Perfomic Acid
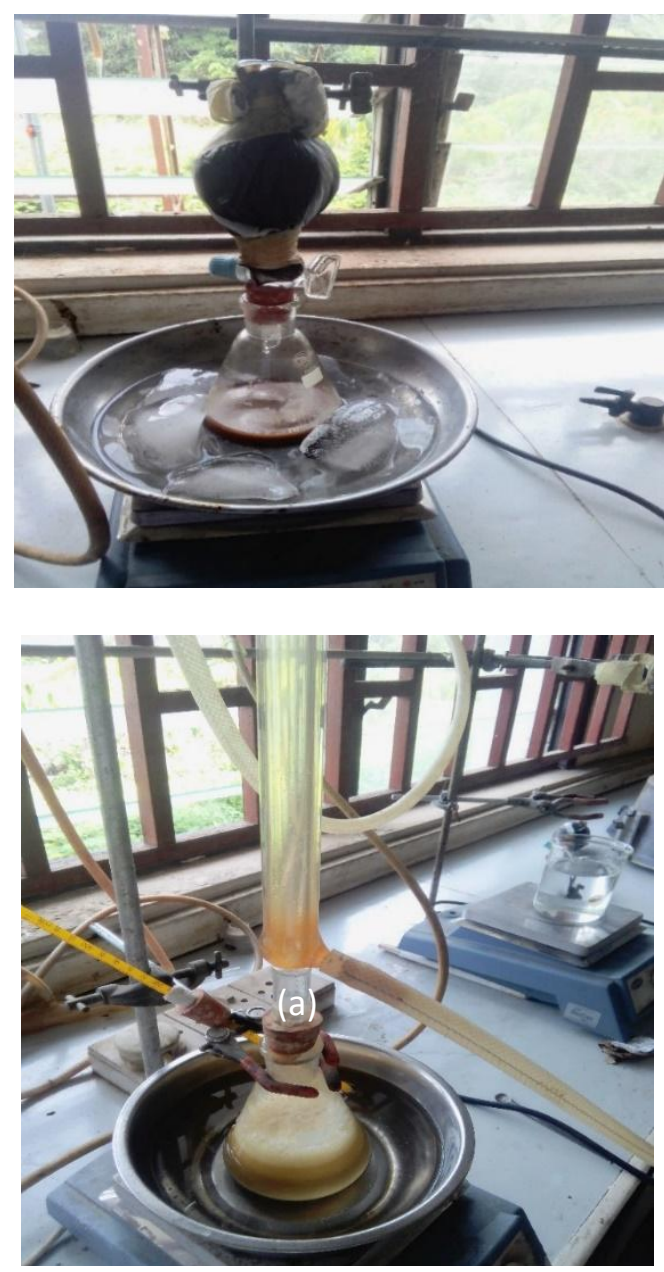

Figure 1a: Equilibration of RSO

Figure 1b: Epoxidation of ERSO Set-up

The reaction temperature was retained at $40{ }^{\circ} \mathrm{C}$, and stirred continuously for 3 hours. The progress of the reaction was examined closely by taking aliquot at different time to measure oxirane content. The experiment was repeated at temperatures of $50,60,70{ }^{\circ} \mathrm{C}$. The physico- chemical properties and fatty acid profile are given in Table $1 \& 2$ respectively.
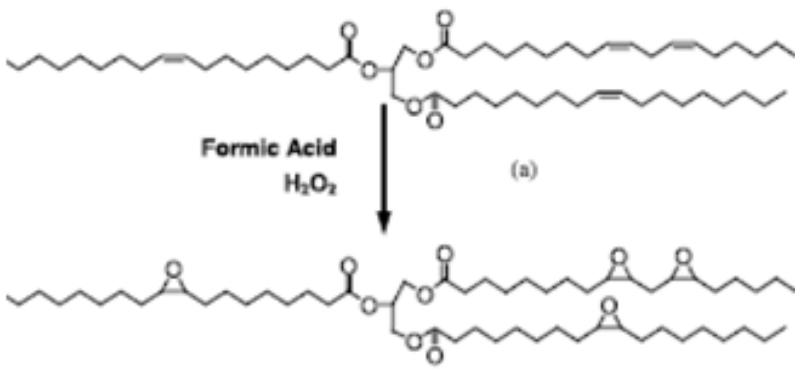

(b)

Figure 2: Production pathway of epoxidized rubber seed oil (ERSO)

\section{RESULT AND DISCUSSIONS}

Table I: The physico- chemical properties of RSO and ERSO at different temperatures

\begin{tabular}{|c|c|c|c|c|c|}
\hline Properties & RSO & $\begin{array}{c}\text { ERSO } \\
\text { at } 40^{\circ} \mathbf{C}\end{array}$ & $\begin{array}{c}\text { ERSO } \\
\text { at } 5^{\circ} \mathbf{C}\end{array}$ & $\begin{array}{c}\text { ERSO } \\
\text { at } 60^{\circ} \mathbf{C}\end{array}$ & $\begin{array}{c}\text { ERSO } \\
\text { at } 7^{\circ} \mathbf{C}\end{array}$ \\
\hline $\begin{array}{c}\text { Specific } \\
\text { gravity }\end{array}$ & 0.874 & 0.876 & 0.874 & 0.877 & 0.879 \\
\hline
\end{tabular}

Palmitic acid

Stearic acid

Oleic acid

Linoleic acid

Linolenic acid

13.60

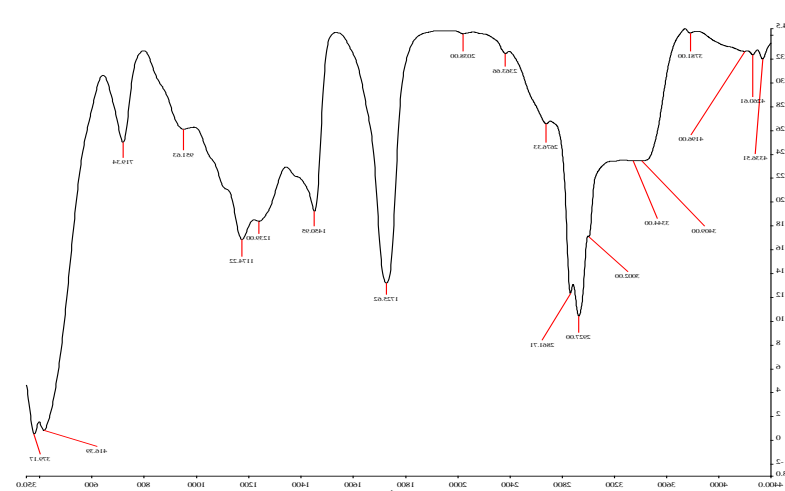

Figure 3: FTIR spectrum of extracted rubber seed oil (RSO)

Table III: Characteristics peak of RSO and their functional groups

\begin{tabular}{|c|c|c|}
\hline Sample & $\begin{array}{c}\text { Band }\left(\mathrm{cm}^{-}\right. \\
1)\end{array}$ & Assignment \\
\hline \multirow{8}{*}{ RSO } & 5781 & O-H Overtone \\
\hline & 5002 & Combination asymmetric bending of $\mathrm{O}-\mathrm{H}$ \\
\hline & 4556 & Stretching frequency of the of the epoxy ring \\
\hline & 4260 & Stretching O-H \\
\hline & $1725-1450$ & Stretching $\mathrm{CH}_{3}$ of $\left(\mathrm{CH}_{3}\right)_{2}$ \\
\hline & $1259-1174$ & bending $\mathrm{C}-\mathrm{O}-\mathrm{C}$ frequency of ethers \\
\hline & 951 & bending $\mathrm{C}-\mathrm{O}$ of oxirane \\
\hline & 719 & bending $\mathrm{C}-\mathrm{C}$ of carbon atom \\
\hline
\end{tabular}

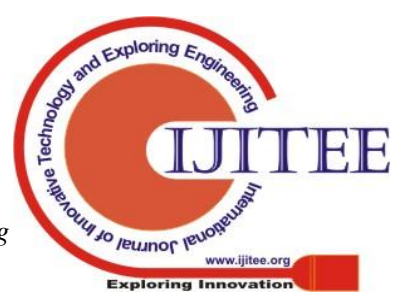




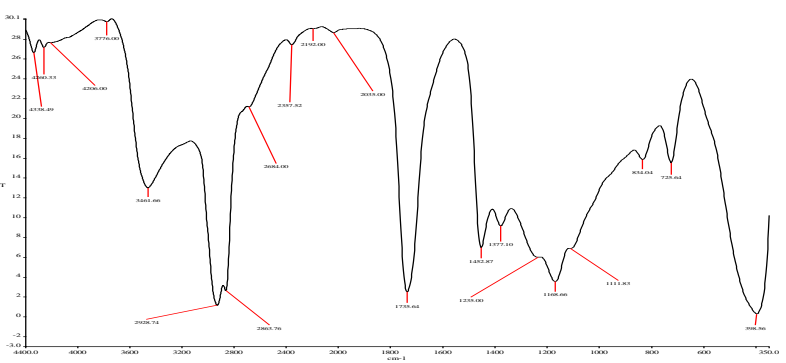

Figure 4: FTIR spectrum of epoxidized rubber seed oil (ERSO)

Table IV: Characteristics peak of ERSO and their functional groups

\begin{tabular}{|c|l|l|}
\hline Sample & \multicolumn{1}{|c|}{$\begin{array}{c}\text { Band } \mathbf{( \mathbf { c m } ^ { - }} \\
\text { ( })\end{array}$} & \multicolumn{1}{c|}{ Assignment } \\
\hline \multirow{4}{*}{ ERSO } & 4338 & O-H Overtone \\
\cline { 2 - 3 } & 3461 & Combination bending of O-H \\
\cline { 2 - 3 } & 2928 & Stretching frequency of the epoxy ring \\
\cline { 2 - 3 } & 2865 & O-H stretching \\
\cline { 2 - 3 } & $1255-1377$ & bending C-H of $\mathrm{CH}_{2}$ and $\mathrm{CH}$ \\
\cline { 2 - 3 } & $1111-1165$ & Stretching of ethers \\
\cline { 2 - 3 } & 725 & Bending of oxirane group \\
\hline
\end{tabular}

The FTIR spectrum of RSO showed a bending vibrational mode at $951 \mathrm{~cm}$ which depicted the presence of $\mathrm{C}-\mathrm{H}$ of $\mathrm{C}=$ $\mathrm{C}-\mathrm{H}$. This disappears in the FTIR spectrum of ERSO which implies the disappearance of $\mathrm{C}=\mathrm{C}-\mathrm{H}$ bond. There was an absorption frequency of $1377 \mathrm{~cm}^{-1}$ appearing in the spectrum of ERSO which showed the presence of cyclic ether group of the epoxy functionality. This on the overall, showed that $\mathrm{C}=\mathrm{C}$ of $\mathrm{RSO}$ was effectively and efficiently converted to $\mathrm{C}-\mathrm{O}-\mathrm{C}$ of epoxy functionality.

\section{A. Effect of temperature on epoxidation of rubber seed oil with performic acid}

Plots of \% oxirane versus time for the epoxidation at different temperatures and time is shown in Figure 4. These plots illustrates that the reaction is rapid at a higher temperature. At $40{ }^{\circ} \mathrm{C}$, the reaction rate increases somehow slowly with time. However, at temperature of $50{ }^{\circ} \mathrm{C}$ and above are linear at the begining of the reaction (up to about 3 hours of the reaction) when an upward curvature is obtained. This upward curvature is believed to mark the begining of the oxirane ring opening reaction that could lead to a decrease in the epoxide content of the reaction mixture. It has been reported by [3] that the time attaining these maximim epoxide content decreases as the temperature increases and are much shorter for epoxidation with performic acid thereby making epoxidation of RSO with performic acid more economical. These results therefore propose that favourable level of epoxidation could be achieved at mild temperatures of $\left(60-70{ }^{\circ} \mathrm{C}\right)$ at which epoxide appears to be minimal.

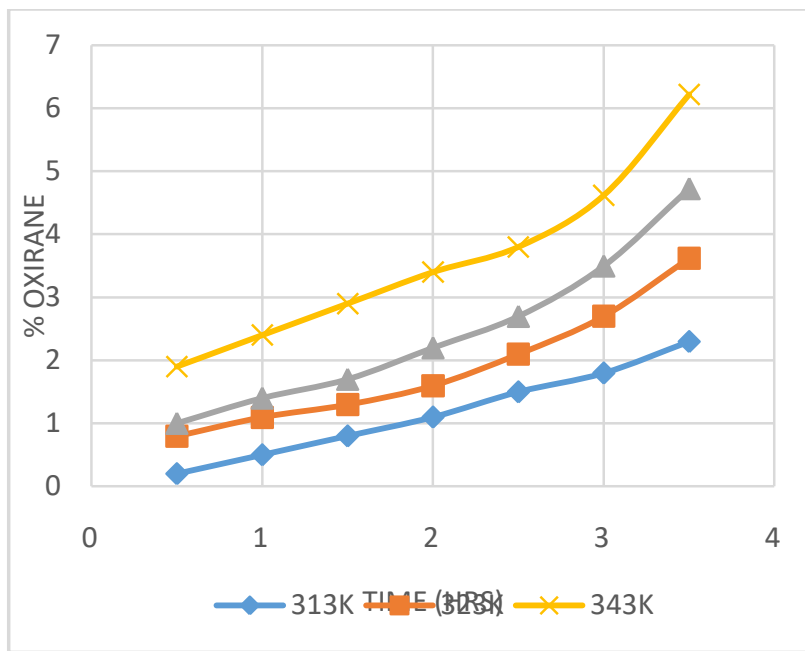

Figure 5: Plots of \% oxirane content versus time at different temperatures.

\section{B. Kinetics analysis of epoxidation}

The rate expression for the epoxidation was reported by [5] $\left.\operatorname{In}\left\{\left[\mathrm{H}_{2} \mathrm{O}_{2}\right]\right\}-[E P]\right\}=k[\mathrm{RCOOH}]_{O} t+\operatorname{In}\left[\mathrm{H}_{2} \mathrm{O}_{2}\right]$

(1)

\section{where}

EP represents the epoxides and subscript denotes the initial concentration.

$\left[\mathrm{H}_{2} \mathrm{O}_{2}\right]_{o}$ and $[\mathrm{HCOOH}]_{O}$ are the initial concentrations of hydrogen peroxide and formic acid respectively. $K$ is the rate constant while $t$ is the time of reaction. From equation 1 plots of $\left.\operatorname{In}\left\{\left[\mathrm{H}_{2} \mathrm{O}_{2}\right]\right\}-[E P]\right\}$ versus $\mathrm{t}$ is assumed to be linear from which the $K$ for epoxidation can be obtained. Figure 6 illustrates the plots of $\left.\operatorname{In}\left\{\left[\mathrm{H}_{2} \mathrm{O}_{2}\right]\right\}-[E P]\right\}$ versus $t$ different temperatures. The nonconformities of linearity suggests to be as a result of oxirane degradation. The values of the $K$ were obtained from the initial linear plots and are given in Table 5. These high $K$ values for the epoxidation with performic acid can be attributed to the stronger acidic nature and the active oxygen nature of formic acid which makes it more efficient and effective than acetic acid in shuttling the active oxygen site between the aqueous phase and oil phase which is centered on epoxidation.

Table V: Value of $\mathrm{K}$, calculated for the epoxidation of RSO by performic acid obtained at different temperatures

\begin{tabular}{|c|c|}
\hline $\begin{array}{c}\text { Temperature of reaction } \\
(\mathrm{K})\end{array}$ & $\begin{array}{c}\text { Rate constant } \\
\text { Performic acid } \mathrm{k} \times 10^{5}\left(\mathrm{~L} \mathrm{~mol}^{-1} \mathrm{~s}^{-1}\right)\end{array}$ \\
\hline 313 & 1.61 \\
\hline 323 & 6.43 \\
\hline 333 & 9.32 \\
\hline 343 & 17.64 \\
\hline
\end{tabular}




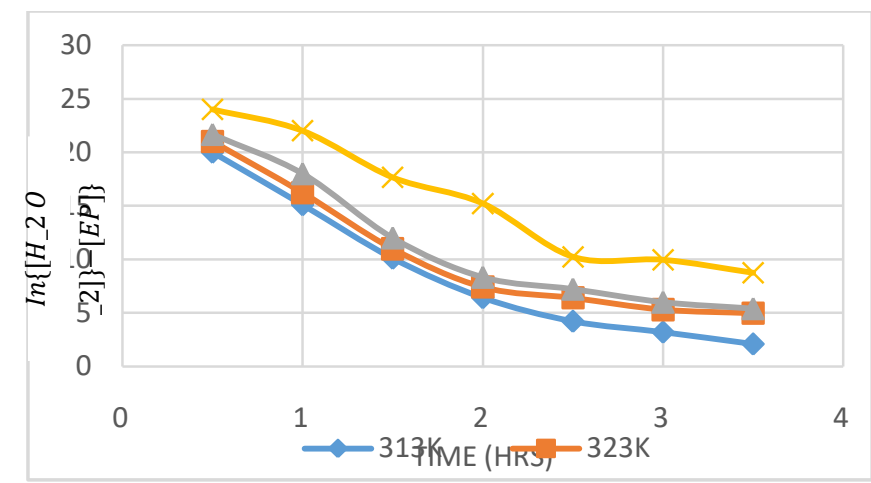

Figure 6: Plots of $\left.\operatorname{In}\left\{\left[\mathrm{H}_{2} \mathrm{O}_{2}\right]\right\}-[E P]\right\}$ versus reaction time at different temperatures

The activation energy $\left(E_{a}\right)$ and the enthalpy of reation $(\Delta H)$ of epoxidation of RSO with performic acid are $67 \mathrm{KJmol}^{-1}$ add $62.4 \mathrm{KJmol}^{-1}$. These values are lower than $\mathrm{E}_{\mathrm{a}}=74 \mathrm{KJmol}^{-}$ ${ }^{1}$ and $\Delta \mathrm{H}=68 \mathrm{KJmol}^{-1}$ as reported earlier for epoxidation of RSO with peracetic acid [5]. These thermodynamic parameters tend to indicate that it is energetically feasible and viable to epoxidize rubber seed oil with performic acid than with peracetic acid.

\section{CONCLUSION}

From the results obtained from this study, it can be inferred that epoxidized rubber seed oil with high epoxide content is favoured by a high temperature, but epoxidation is accompanied by oxirane cleavage which makes it suitable in production of plasticizers. Highest epoxide content of 6.22 is achieved at high temperature of $343 \mathrm{~K}$. However, from the kinetic and thermodynamic values obtained for epoxidation, it simply indicates that an increase in the reaction temperature leads rapid epoxide formation and this is very beneficial for scaling up making of epoxidized oils employing in situ method.

\section{ACKNOWLEDGEMENT}

Special thanks goes to Covenant University for sponsorship of this research work for publication.

\section{ETHICS}

This paper has neither been published nor submitted in any domestic or abroad journals.

\section{REFERENCES}

1. Abdullah B.M. and Salimon J. (2009). Physicochemical characteristics of Malaysian rubber (Hevea brasiliensis) seed oil. Eur J Sci Res. 31(3):437-445

2. Adhvaryu, A., Liu Z. and Erhan, S.Z. (2002). Epoxidized Soybean oil as a potential source of high temperature lubricants. Ind Crops Prod. 15(1): 247-254

3. Aigbodion, A.I, Okieimen, F.E. and Bakare, I.O. (2001). Investigation of oxirane ring opening reaction in epoxidized rubber seed oil quality assessment and authentication. Journal oil Technology Association Indian 33(3): 16-19.

4. Aigbodion, A.I, Pillai, K.S.C., Bakare, I.O. and Yahaya, L. E. (2001). Synthesis, characterization and evaluation of heated rubber seed oil modified alkyd resins as binders in surface coatings. Indian J. of chemical technology. 8(2): 378-384.

5. Aigbodion, A.I, Okieimen, F.E. and Bakare, I.O. (1999). In situ epoxidation of rubber seed oil by peracetic acid. Nigeria Journal of applied Sci. 17(2): 27-36

6. Aigbodion, A.I, Menon, A.R.R and Pillai, C.K.S. (2000) Processability characteristics and physico-mechanical properties of natural rubber modified with rubber seed oil and epoxidized rubber seed oil. J Appl Polym Sci. 77(5):1413-1418. doi: 10.1002/10974628(20000815)77:7<1413::AID-APP23.0.CO;2-7.

7. Blayo, A. Gandini, J.F. and Nest L.E. (2001). Chemical and rheological characterization of some vegetable oils derivatives commonly used in printing inks. Ind. crops Prod. 14(2):155-167

8. Canakci M, Van Gerpen J (2001). Biodiesel production from oils and fats with high free fatty acids. Transactions of ASAE. 44(6):1429-1436

9. Ikwuagwu, O.E., Ononogbu, I.C. and Njoku, O.U. (2000). Production of biodiesel using rubber seed oil. Ind. Crops. Prod. 12(1):57-62

10. Iyayi A.F, Akpata P.O, Ukpeoyibo U (2008). Rubber seed processing for value added latex production in Nigeria. Afri. J. Agri. Res. 3(7):505-509.

11. Joseph R, Madhusoodhanan, K.N., Alex, R, Varghese, S., George, K.E., and Kuriakose B. (2004). Studies on epoxidized rubber seed oil as secondary plasticizer/stabilizer for PVC, plastics, rubber and composites. 33(3):217-222. doi: 10.1179/146580104225020974.

12. Obanla, O.R., Udonne, J.D., Ajani, O.O., Omodara, O.J. and Omolewa, D.A. (2018). Extraction, comparative study and property evaluation synthesized bar soap from locally sourced rubber (Hevea Brasiliensis) seed oil and palm kernel oil. International

13. Journal of Mechanical Engineering and Technology (IJMET) 9(12):308-319

14. 2. Onyeike, E.N. and Acheru, G.N. (2002). Chemical composition of selected Nigerian oil seeds and physicochemical properties of the oil extracts. Food Chem. 77:431-437. doi: 10.1016/S0308 8146(01)00377-6.

15. Ramadhas, A.S., Jayaraj, S and Muraleedharan, C. (2009). Biodiesel production from high FFA rubber seed oil fuel. 84(4):335-340

16. Salimon, J. and Abdullah, B.M. (2009). A study on the thermal properties and solid fat content of Malaysian rubber seed oil. The Malaysian Journal of analytical Sciences. 13(2): 1-7.

17. Udonne, J. D. and Alade, B.O. (2016). Development of biobased lubricant from locust bean seed oil. International Journal of Scientific \& Engineering Research. 7(3): 491-500

\section{AUTHORS PROFILE}

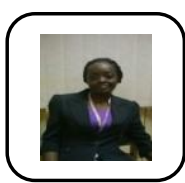

Oyinlola Obanla holds a $1^{\text {st }}$ and $2^{\text {nd }}$ degree in chemical Engineering. A versatile Researchers that specializes in Polymer Engineering

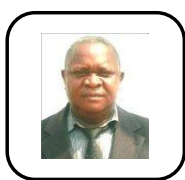

Prof. Joseph Udonne is a chemical Engineer who specializes in recovery resources and Polymer Technology.

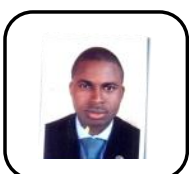

Prof. Olayinka Ajani is a researcher with area of specialization in organic synthesis and medicinal chemistry 